venous return anatomy plays a pivotal role in the management of these patients.

\footnotetext{
References

1. Alsoufi B, Cai S, Van Arsdell GS, Williams WG, Caldarone CA, Coles JG. Outcomes after surgical treatment of children with partial anomalous pulmonary venous connection. Ann Thorac Surg. 2007;84:2020-6.

2. Marianeschi SM, Cannata A, Uricchio N, Pedretti S, Vignati G. Partial anomalous connection of both superior pulmonary veins. Ann Thorac Surg. 2012;94:649-51.
}

3. White CS, Baffa JM, Haney PJ, Pace ME, Campbell AB. MR imaging of congenital anomalies of the thoracic veins. Radiographics. 1997;17: 595-608.

4. Buz S, Alexi-Meskishvili V, Villavicencio-Lorini F, Yigitbasi M, Hübler M, Weng Y, et al. Analysis of arrhythmias after correction of partial anomalous pulmonary venous connection. Ann Thorac Surg. 2009;87:580-3.

5. Gokaslan G, Ustunsoy H, Deniz H, Baspinar O, Guzel G, Ozcaliskan O, et al. Lateral cavoatriotomy for partial anomalous pulmonary venous connection to the superior vena cava. Ann Thorac Cardiovasc Surg. 2013; 19:216-21.

\title{
Living related donor middle lobe lung transplant in a pediatric patient
}

\author{
Takahiro Oto, MD, Kentaroh Miyoshi, MD, Seiichiro Sugimoto, MD, and Masaomi Yamane, MD, \\ Okayama, Japan
}

There are 2 major problems with the availability of lung transplants for very young patients. Younger donors are limited; only 394 of 25,874 donors $(1.5 \%)$ in the United States and 1 of $251(0.4 \%)$ in Japan were 5 years old or younger. ${ }^{1-3}$ There are significant size discrepancies between older donors and very young recipients. These problems have been addressed by living related donor lower lobe lung transplants for critically ill children. ${ }^{4}$ Adult lower lobe grafts, however, may be too large for a small toddler's chest. Living related donor middle lobe transplants would seem ideal, but this graft has been considered inadequate for transplant. ${ }^{5}$ This report describes the first successful living related donor middle lobe lung transplant in a very young patient.

The recipient was a 3-year-old boy (height, $91 \mathrm{~cm}$; weight, $12 \mathrm{~kg}$ ) with a combination of obstructive and restrictive lung dysfunction as a result of graft-versus-host disease after a bone marrow transplant at the age of 1 year. The patient required in-hospital intensive care as a result of dyspnea and repeated pneumomediastinum (Figure 1, $A$ and $C$ ). The patient was thought to be unable to survive long enough for a size-matched brain-dead pediatric donor lung to become available in Japan. Living

From the Department of Thoracic Surgery, Okayama University Graduate School of Medicine, Dentistry and Pharmacological Sciences, Okayama, Japan.

Disclosures: Authors have nothing to disclose with regard to commercial support.

Received for publication Aug 13, 2014; revisions received Oct 20, 2014; accepted for publication Oct 25, 2014; available ahead of print Nov 27, 2015

Address for reprints: Takahiro Oto, MD, 2-5-1, Shikata-cho, Kita-ku, Okayama 7008558, Japan (E-mail: oto@md.okayama-u.ac.jp).

J Thorac Cardiovasc Surg 2015;149:e42-4

$0022-5223 / \$ 36.00$

Copyright (c) 2015 by The American Association for Thoracic Surgery

http://dx.doi.org/10.1016/j.jtcvs.2014.10.102 related donor lobar lung transplant was considered as an alternative therapy. The recipient's mother seemed the best immunologic candidate as lung donor, because she had donated her bone marrow to her son. Computed tomography revealed that the volumes of the donor's lower and middle lobes were estimated to be $544 \%$ and $216 \%$ larger than that of the recipient hemithorax, respectively. Threedimensional computed tomography also revealed that the middle lobe had single pulmonary arterial, venous, and bronchial branches, and there were no other small branches. The middle lobe lung transplant was therefore planned, and informed consent was obtained. This procedure was approved by the institutional ethics board of Okayama University.

\section{CLINICAL SUMMARY \\ Donor Operation}

Because the middle lobe had single pulmonary arterial, venous, and bronchial branches, no vascular or bronchial reconstruction was required for the donor operation.

\section{Recipient Operation}

After right pneumonectomy, the middle lobe graft was rotated $45^{\circ}$ clockwise and was fitted into the recipient chest cavity. All the vascular and bronchial anastomoses were performed in an end-to-end fashion. The middle lobe bronchus was trimmed as short as possible to avoid torsion of the implanted lobe and was anastomosed to the recipient's right main bronchus. After completion of the bronchial anastomosis, the middle lobe graft was inflated for inspection of positional relationship. The middle lobe vein was then anastomosed to the recipient's right upper vein. Pulmonary arterial anastomosis was the most challenging part. Because the middle lobe artery took 

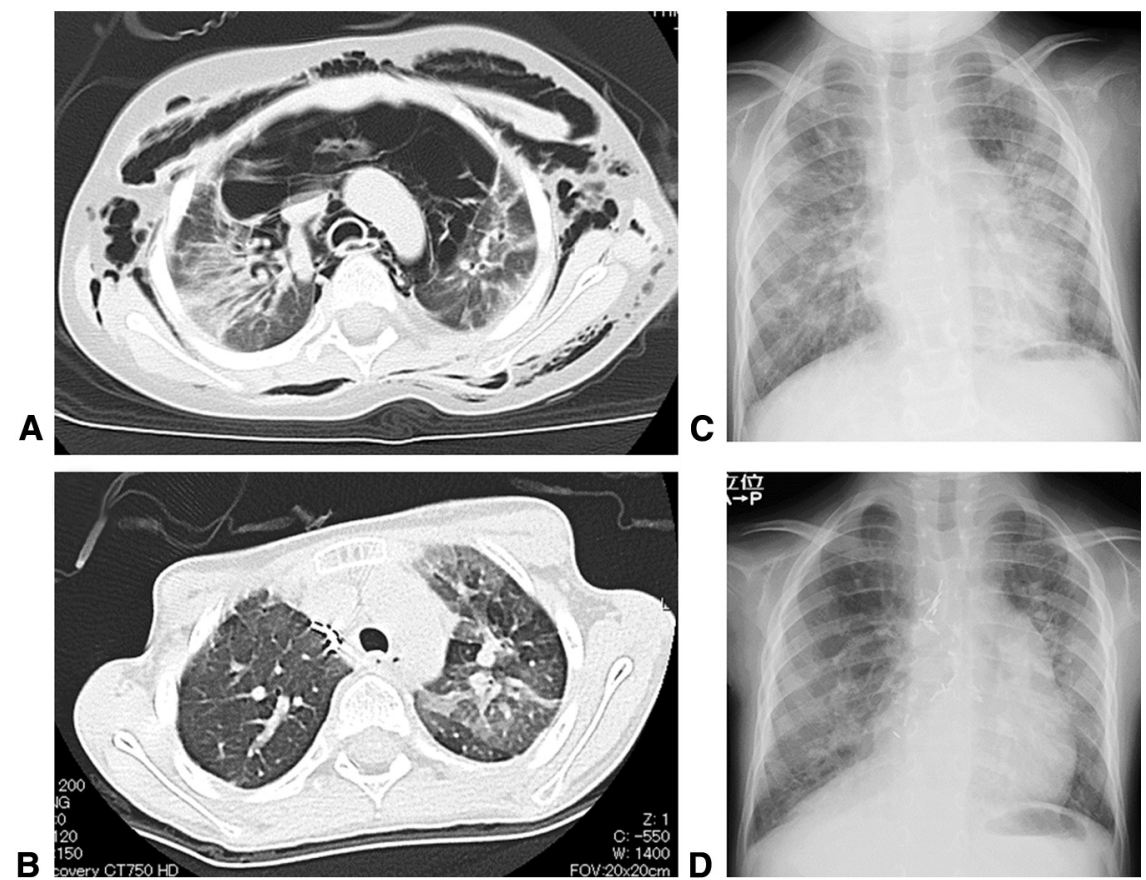

FIGURE 1. A, Recipient computed tomography before the middle lobe transplant. B, Computed tomography 1 year after the middle lobe transplant. $\mathrm{C}$, Recipient chest radiography before the middle lobe transplant. D, Chest radiography 1 year after the middle lobe transplant.

off toward the apex (Figure 2, A), the recipient's main pulmonary artery was dissected proximally to gain additional length. The edges of these arteries were cut at an angle, and end-to-end arterial anastomosis was created to bridge over the middle lobe bronchus to avoid kinking (Figure 2, B).
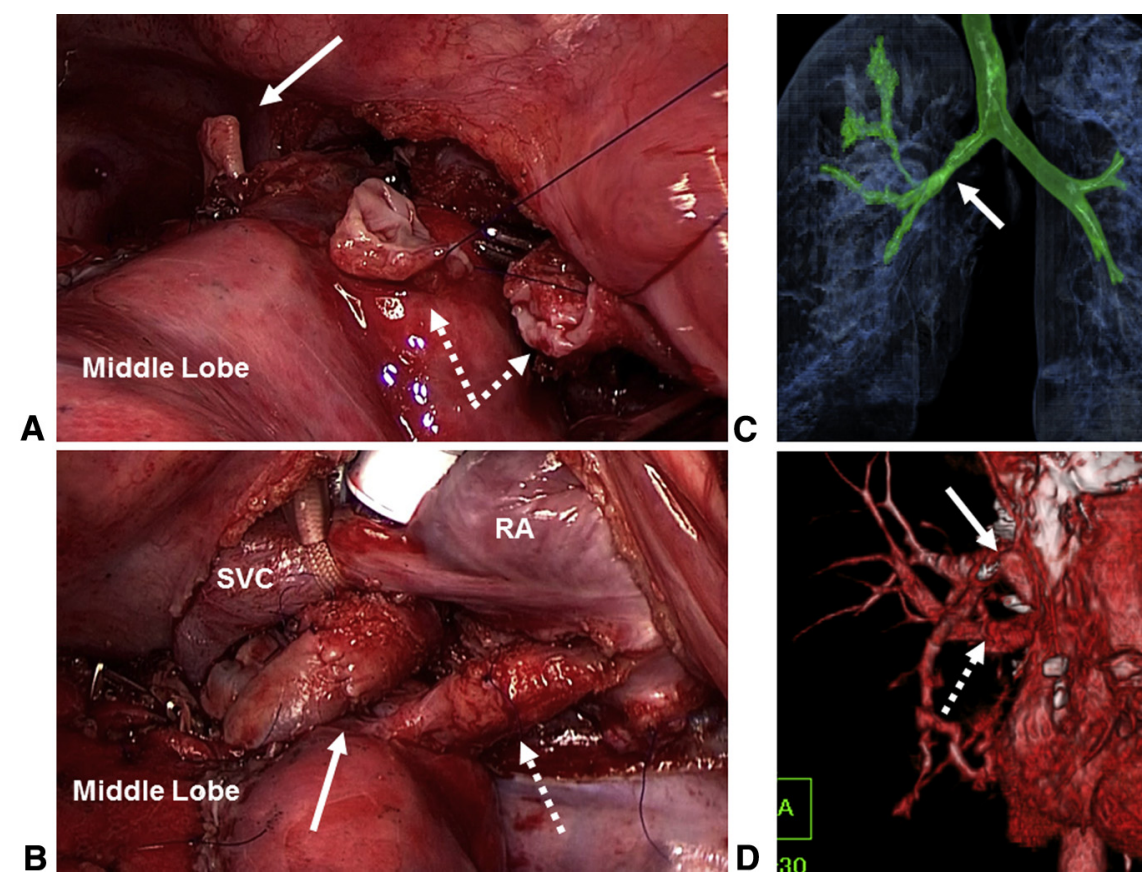

FIGURE 2. A, Initiation of the middle lobe venous anastomosis (broken arrow). The middle lobe artery took off toward the apex (solid arrow). $\mathrm{B}$, Bronchial, venous, and arterial anastomoses were completed. C, The 3-dimensional computed tomographic scan shows the middle lobe bronchial anastomosis 1 year after the transplant (arrow). D, The 3-dimensional computed tomographic scan shows arterial (arrow) and venous (broken arrow) anastomoses 1 year after the middle lobe transplant. $S V C$, Superior vena cava; $R A$, right atrium. 
The recipient was extubated at 5 days after the transplant, and the bronchial and vascular anastomoses appeared to exhibit no kinking and obstruction (Figure 2, $C$ and $D$ ). The recipient was discharged from the hospital without oxygen inhalation.

The implanted middle lobe remained clear on chest radiography and computed tomography 1 year after the transplant (Figure 1, $B$ and $D$ ). The values for the ratio of $\mathrm{PaO}_{2}$ to inspired oxygen fraction before transplant and 1 year after the transplant were 127 and 384, respectively. Percentage of forced expiratory volume in 1 second values for the donor before and 3 months after the donor operation were $136 \%$ and $103 \%$, respectively. The donor and the recipient have been enjoying their healthy lives after the transplant.

\section{DISCUSSION}

Middle lobes from adult living donors could contribute to saving small pediatric patients. Limitations of this procedure are as follows: (1) The donor middle lobe should have single arterial, venous, and bronchial branches.
Otherwise, the requirement of patch repair may increase the potential surgical risks of the donor operation. (2) An additional contralateral lung transplant may be required as the recipient grows.

Living donor lingula or segmental lung transplant might be an alternative strategy.

\section{References}

1. Organ Procurement and Transplantation Network [Internet]. Washington: US Department of Health \& Human Services; 2014. Available at: http://optn. transplant.hrsa.gov/latestData/rptData.asp. Accessed August 1, 2014.

2. Japan Organ Transplant Network [Internet]. Tokyo: Public Interest Incorporated Foundation Japan Organ Transplant Network; 2014. Available at: http://www. jotnw.or.jp/datafile/offer_brain.html. Accessed August 1, 2014.

3. Oto T, Okada Y, Bando T, Minami M, Shiraishi T, Nagayasu T, et al. Registry of the Japanese Society of Lung and Heart-Lung Transplantation: the official Japanese lung transplantation report 2012. Gen Thorac Cardiovasc Surg. 2013; 61:208-11.

4. Oto T. Living donor lobar lung transplantation. In: Goldfarb S, Benden C, Sweet S, Kirklin JK, eds. ISHLT monograph series: pediatric lung transplantation. Birmingham (AL): University of Alabama at Birmingham; 2013: $220-7$.

5. Starnes VA, Barr ML, Cohen RG. Lobar transplantation. Indications, technique, and outcome. J Thorac Cardiovasc Surg. 1994;108:403-10; discussion 410-1.

\title{
Mycotic aortic aneurysm in a child with aortic coarctation
}

\author{
Bradley LeNoir, MD, MBA, Walter F. DeNino, MD, Scott M. Bradley, MD, and Minoo N. Kavarana, MD, \\ Charleston, SC
}

Mycotic aneurysm is a rare sequela of aortic coarctation, seen both before and after repair. Mycotic aneurysm is precipitated by aortic endarteritis, and patients may present with a nonspecific constellation of symptoms. ${ }^{1}$ We present a case of simultaneous surgical repair of aortic coarctation and mycotic aneurysm.

\section{CASE SUMMARY}

A 10-year-old boy was referred to a rheumatologist after 3 months of intermittent fevers and a bilateral, painful rash of

From the Division of Cardiothoracic Surgery, Medical University of South Carolina, Charleston, SC.

Disclosures: Authors have nothing to disclose with regard to commercial support.

Received for publication Oct 22, 2014; accepted for publication Nov 6, 2014; available ahead of print Dec 18, 2014.

Address for reprints: Minoo N. Kavarana, MD, Medical University of South Carolina, Pediatric Cardiac Surgery, CSB 424, 96 Jonathan Lucas St, Charleston, SC 29425 (E-mail: kavarana@musc.edu).

J Thorac Cardiovasc Surg 2015;149:e44-6

$0022-5223 / \$ 36.00$

Copyright (c) 2015 by The American Association for Thoracic Surgery

http://dx.doi.org/10.1016/j.jtcvs.2014.11.043 the legs and feet. C-reactive protein level and erythrocyte sedimentation rate were elevated. He was hypertensive, with diminished femoral pulses and an arm-leg blood pressure gradient of $40 \mathrm{~mm} \mathrm{Hg}$. An echocardiogram revealed an aortic coarctation. Computed tomographic angiography of the aorta confirmed coarctation and additionally revealed a $22-\mathrm{mm}$ pseudoaneurysm distal to the coarctation (Figure 1). The patient was expeditiously taken to the operating room for aortic coarctation and aneurysm repair. With left heart bypass (left atrial appendage and descending thoracic aorta cannulation), multiple collaterals were controlled or ligated. A large, thin-walled saccular aneurysm distal to the coarctation was identified (Figure 2). The aneurysm and coarctation were excised en bloc distal to the left subclavian artery. The left subclavian artery was ligated distally and was turned down as a flap and tubularized with an aortic homograft for repair of the resultant defect. The patient tolerated the procedure without complication. The crossclamp time was 90 minutes, and the total cardiopulmonary bypass time was 105 minutes. Intraoperative cultures were positive for pansensitive Streptococcus mitis. The patient was started 